\title{
Neck circumference as an independent predictor for NAFLD among postmenopausal women with normal body mass index
}

Jie Shi ${ }^{1 \dagger}$, Zixuan Wang ${ }^{2 \dagger}$, Weiwei Zhang ${ }^{1 \dagger}$, Yixin Niu ${ }^{1}$, Ning Lin' ${ }^{1}$, Xiaoyong Li ${ }^{1}$, Hongmei Zhang ${ }^{1}$, Guang Ning ${ }^{3}$, Jiangao Fan ${ }^{2 *}$, Li Qin ${ }^{1 *}$, Qing Su ${ }^{1 *}$ and Zhen Yang ${ }^{1 *}$ (1)

\begin{abstract}
Background: Neck circumference, a proxy for upper-body subcutaneous fat, is a unique and pathogenic fat depot that confers additional metabolic risk. The purpose of present study was to determine whether neck circumference associates with nonalcoholic fatty liver disease (NAFLD) in postmenopausal women with normal body mass index.

Methods: A cross-sectional survey $(n=2492)$ and a 3.1-year follow-up investigation $(n=1354)$ were conducted among Chinese postmenopausal women with normal BMI (18.5 to $<25 \mathrm{~kg} / \mathrm{m}^{2}$ ). Neck circumference was measured horizontally at the lower margin of the laryngeal prominence.

Results: In the cross-sectional analysis, large neck circumference was associated with the presence of NAFLD (odds ratio 2.28; 95\% Cl 1.74-2.98; highest tertile versus lowest tertile) after adjustment for confounding factors. Among 1354 subjects without the NAFLD at baseline, 429 (31.7\%) incident NAFLD cases occurred at 3.1 years. Neck circumference was positively associated with triglycerides, homeostasis model assessment of insulin resistance, C-reactive protein, and negatively associated with high-density lipoprotein cholesterol and adiponectin. Individuals with large baseline neck circumference had a significantly higher risk of NAFLD than those with small neck circumference. The multivariable adjusted hazard ratio was $1.42(95 \% \mathrm{Cl} 1.15-1.97 ; p$ for trend $=0.004)$ for the highest versus the lowest tertile of neck circumference, and was $1.22(95 \% \mathrm{Cl} 1.10-1.41 ; p=0.006)$ per 1-standard deviation increment in neck circumference.
\end{abstract}

Conclusions: Among postmenopausal women with normal BMI, relatively large neck circumference levels are associated with an increased risk of NAFLD.

Keywords: Neck circumference, Nonalcoholic fatty liver disease, Postmenopausal women, Normal body mass index

*Correspondence: fattyliver2004@126.com; qinli@xinhuamed.com.cn; suqing@xinhuamed.com.cn; yangzhen@xinhuamed.com.cn

†Jie Shi, Zixuan Wang, and Weiwei Zhang contributed equally to this work ${ }^{1}$ Department of Endocrinology, Xinhua Hospital, Shanghai Jiao Tong University School of Medicine, Shanghai, China

2 Department of Gastroenterology, Shanghai Key Laboratory of Children's Digestion and Nutrition, Xinhua Hospital, Shanghai Jiao Tong University School of Medicine, Shanghai, China

Full list of author information is available at the end of the article

\section{Introduction}

Nonalcoholic fatty liver disease (NAFLD) is characterized by excessive fat accumulation in the liver with the absence of alcohol and other liver diseases. It is well established that adiposity is a major contributor to NAFLD. Data from epidemiological studies revealed that NAFLD occurrence in up to $70 \%$ of overweight adults worldwide [1] and in $90 \%$ of morbidly obese adults globally [2]. Nonetheless, a remarkable proportion of individuals having NAFLD with a relatively normal body original author(s) and the source, provide a link to the Creative Commons licence, and indicate if changes were made. The images or other third party material in this article are included in the article's Creative Commons licence, unless indicated otherwise in a credit line to the material. If material is not included in the article's Creative Commons licence and your intended use is not permitted by statutory regulation or exceeds the permitted use, you will need to obtain permission directly from the copyright holder. To view a copy of this licence, visit http://creativecommons.org/licenses/by/4.0/. The Creative Commons Public Domain Dedication waiver (http://creativeco mmons.org/publicdomain/zero/1.0/) applies to the data made available in this article, unless otherwise stated in a credit line to the data. 
mass index (BMI), a condition termed as "non-obese" NAFLD. The prevalence of NAFLD was around $10 \%$ in nonobese adults in Western countries, and about 8-19\% of Asians with BMI less than $25 \mathrm{~kg} / \mathrm{m}^{2}$ are also found to have NAFLD [3]. Given this trend, a reliable predictor of NAFLD in nonobese people is essential for its prevention and management.

As we best known, the larger the BMI, the higher the metabolic risk. However, individuals within the same BMI status could have considerable differences in the amount and distribution of regional fat depots, leading to variable metabolic risks $[4,5]$. Numerous researches highlight the metabolic risk conferred by specific patterns of fat distribution, particularly upper body adiposity [6]. Notably, several studies have recently shown that upperbody subcutaneous adipose tissue, estimated by neck circumference, is a unique fat depot that confer additional metabolic risks beyond generalized and abdominal adiposity $[7,8]$. It is reported that neck circumference levels are significantly associated with hyperlipidemia, impaired glucose homeostasis, and insulin resistance, especially in women [7]. All of these supported the investigation of a possible association of neck circumference with NAFLD.

Due, in part, to a transfer from subcutaneous to abdominal visceral fat, women after menopause are prone to metabolic changes [9]. Such metabolic alterations are associated with increased NAFLD risk among normal BMI populations. However, studies that assess neck fat accumulation, as a proxy for upper-body subcutaneous fat, and its relationship with NAFLD among postmenopausal women with normal BMI are still lacking. In the current study, we evaluated the relationship between neck circumference and NAFLD among postmenopausal women with normal BMI.

\section{Participants and methods \\ Study subjects}

Participants were recruited from the China Cardiometabolic Disease and Cancer Cohort (4C) Study, a nationwide prospective cohort study investigating the associations of metabolic factors with specific clinical outcomes, including diabetes, cardiovascular disease, cancer, and all-cause mortality $[10,11]$. The data presented in this study are based on the subsamples from the Chongming District in Shanghai, China. From May to November 2011, a total of 2765 postmenopausal women with normal BMI of Chinese origins were enrolled in the study. From June to December 2014, the subjects were invited for follow-up assessments. The cross-sectional survey included 2492 subjects, and the follow-up investigation included 1354 individuals without NAFLD at baseline (Fig. 1). Subjects with the following conditions were excluded from this study: virus hepatitis, autoimmune hepatitis, drug-induced liver disease, current drinkers, ex-drinkers, presence of tumor, biliary obstructive diseases, thyroid dysfunction, total parenteral nutrition, Wilson's disease, severe renal insufficiency, significant hematologic disorders, and current treatment with systemic corticosteroids.

The study protocol was approved by the Ethics Committee of Xinhua Hospital Affiliated to Shanghai Jiao Tong University School of Medicine. Written informed consent was obtained from all participants.

\section{Clinical diagnosis of NAFLD}

Guidelines for the diagnosis of NAFLD proposed by the Asia-Pacific Working Party were used [12]. NAFLD was clinically defined as manifestations of B-mode ultrasonography, after the exclusion of the habit of drinking and the history of specific diseases that could lead to fatty liver. Abdominal ultrasonography was performed by experienced ultrasonographers who were blinded to clinical presentation and laboratory data. Hepatic steatosis was defined as a diffuse increase of fine echoes in the liver parenchyma compared with that in the kidney or spleen parenchyma based on standard criteria.

\section{Anthropometric and biochemical measurements}

Neck circumference was measured horizontally at the lower margin of the laryngeal prominence (Adam's apple), with head erect and eyes facing forward. BMI was calculated as the weight in kilograms divided by the square of the height in meters. Waist circumference was measured at the midpoint between the inferior costal margin and the superior border of the iliac crest on the midaxillary line.

Serum total cholesterol, high-density lipoprotein cholesterol (HDL-C), low-density lipoprotein cholesterol, triglycerides, alanine aminotransferase, aspartate aminotransferase, and $\gamma$-glutamyltranspeptidase were measured on an autoanalyzer (Hitachi 7080; Tokyo, Japan). Venous plasma glucose level was determined by glucose oxidase method (ADVIA-1650 Chemistry System, Bayer, Leverkusen, Germany) and hemoglobin A1c was measured by high-performance liquid chromatography (BIO-RAD, D10, CA). Fasting insulin was measured by RIA (Linco Research, St. Charles, MO). The homeostasis model assessment-insulin resistance (HOMA-IR) was used to assess insulin resistance, which was calculated using the following equation: HOMA-IR = insulin $(\mathrm{uU} /$ $\mathrm{mL})$ * glucose $(\mathrm{mmol} / \mathrm{L}) / 22.5$ [13]. Serum C-reactive protein (CRP) and adiponectin levels were quantified using the enzyme-linked immunosorbent assay (ELISA) kits (DY1707, DY1065; R\&D Systems, Minneapolis, MN). 


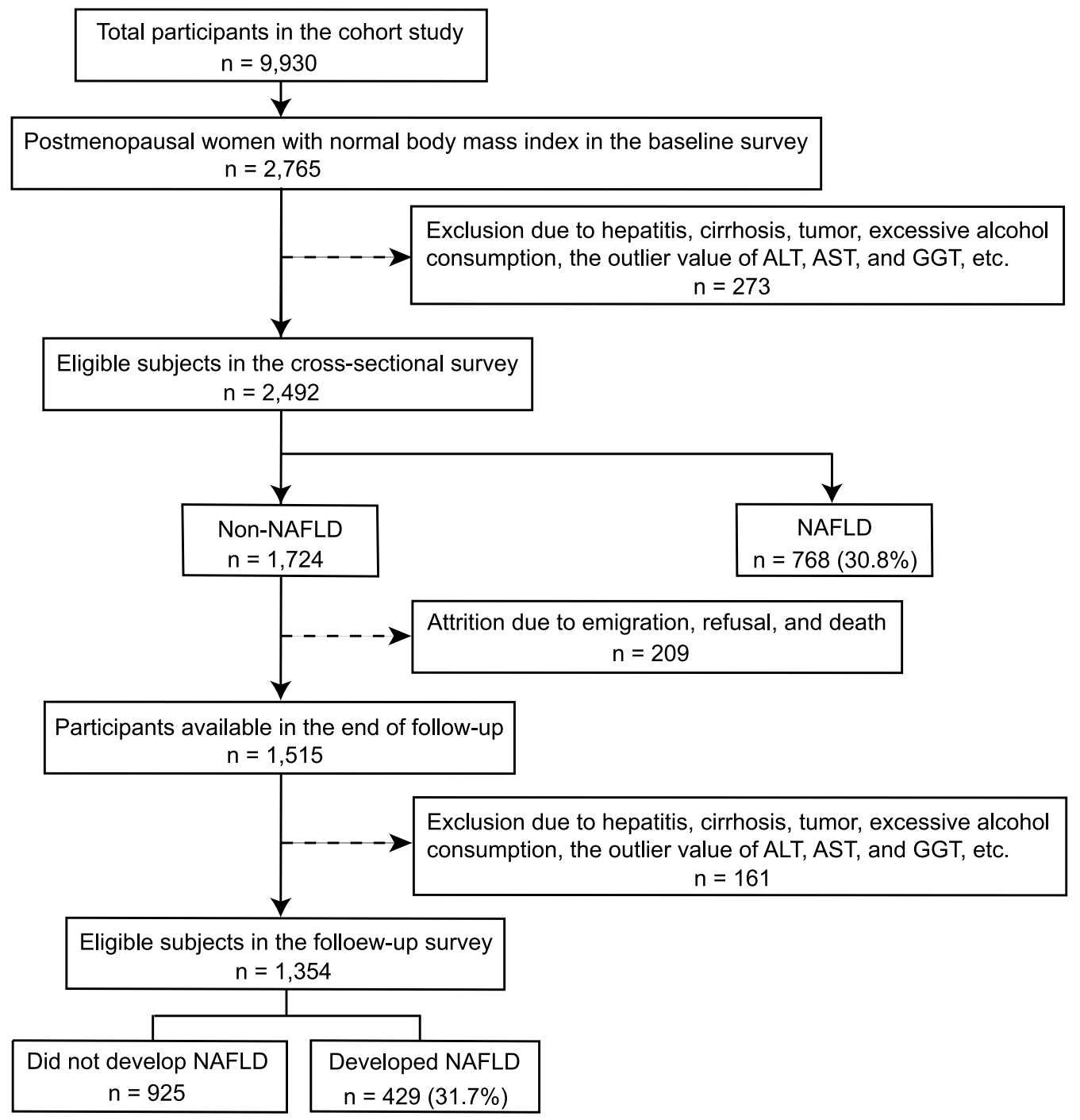

Fig. 1 Overview of the study design

\section{Statistical analysis}

The continuous variables with normal distribution are expressed as means \pm SDs. The continuous variables with skewed distribution are shown as medians (interquartile range) and log-transformed to approximate normality before analysis. Categorical variables are reported as frequencies (\%). For comparisons between groups, we conducted an independent-samples Student t-test for normally distributed variables and a Mann-Whitney $U$ test for variables with highly skewed distributions. The Chi-squared test was performed to compare categorical variables. The correlation coefficients between neck circumference and metabolic parameters were calculated using the Pearson correlation analysis and Partial correlation analysis after adjustment for age, smoking, physical activity, educational attainment, body mass index, and waist circumference. Logistic regression analyses were used to assess the relationship between neck circumference and the prevalence of NAFLD in the cross-sectional survey. Model 1 was adjusted for age, smoking status, physical activity, and educational attainment. Model 2 was further adjusted for BMI and waist circumference. Model 3 was further adjusted for HOMA-IR, CRP, and adiponectin. Model 4 was further adjusted for model 3 variables and fasting glucose, post-loading plasma glucose, systolic blood pressure, diastolic blood pressure. Model 5 was further adjusted for lipid profiles and liver enzymes.

Multivariate Cox regression analyses were run to evaluate the potential association between neck circumference 
and the incidence of NAFLD. Covariates were selected on the basis of biologic interest, well-established risk factors for NAFLD, or associated exposures and outcomes. Variables showing $p<0.05$ in the univariable regression were entered into the multivariable model. Multivariable adjusted models were used to explore the independent effect of neck circumference on the incidence of NAFLD. We also used restricted cubic splines with five knots at percentiles $5 \%, 35 \%, 50 \%, 65 \%$, and $95 \%$ of the distribution to flexibly model to assess the association of neck circumference on a continuous scale and the incidence of NAFLD. Hazard ratios (HRs) and 95\% confidence intervals (CIs) for the relationship between neck circumference and the incidence of NAFLD were generated with the Cox regression models. The surface fitting based on the least square method was performed to assess joint effect of neck circumference with BMI, waist circumference, and HOMA-IR on NAFLD after adjustment for age, smoking status, physical activity, educational attainment, BMI, waist circumference, HOMA-IR, CRP, adiponectin, fasting plasma glucose, post-loading plasma glucose, systolic blood pressure, diastolic blood pressure, lipid profiles, and liver enzymes.

Several risk factors may affect the association between neck circumference and incident NAFLD, particularly age, BMI, waist circumference, CRP, diabetes status, and physical activity. Consequently, we conducted a subgroup analysis to examine whether the relationship between neck circumference and the risk of incident NAFLD was robust in the presence of potential confounders. Subgroups were stratified by age $<65$ years versus age $\geq 65$ years, $\mathrm{BMI}<23 \mathrm{~kg} / \mathrm{m}^{2}$ versus $\mathrm{BMI} \geq 23 \mathrm{~kg} /$ $\mathrm{m}^{2}$, waist circumference $<80 \mathrm{~cm}$ versus waist circumference $\geq 80 \mathrm{~cm}, C R P<3.0 \mathrm{mg} / \mathrm{L}$ versus $C R P \geq 3.0 \mathrm{mg} / \mathrm{L}$, without diabetes versus with diabetes, and low physical activity versus moderate physical activity versus high physical activity.

A 2-tailed $p<0.05$ was considered statistically significant. All analyses were performed using $\mathrm{R}$ version 4.0.2 and SPSS software version 25.0.

\section{Results}

Association between neck circumference and the presence of NAFLD in the cross-sectional survey

The clinical characteristics of the study subjects are shown in Table 1. Subjects with NAFLD had a higher BMI, waist circumference, triglycerides levels, and CRP levels, and a lower HDL-C and adiponectin levels. Larger neck circumference was observed in individuals with NAFLD than those without NAFLD $(33.4 \pm 2.6 \mathrm{~cm}$ vs. $32.0 \pm 2.4 \mathrm{~cm}, p<0.001)$. When stratified by tertiles of neck circumference, the prevalence
Table 1 Characteristics of subjects according to the presence or absence of the nonalcoholic fatty liver diseases at baseline $(n=2492)$

\begin{tabular}{|c|c|c|c|}
\hline Variables & $\begin{array}{l}\text { Non-NAFLD } \\
(n=1724)\end{array}$ & $\begin{array}{l}\text { NAFLD } \\
(n=768)\end{array}$ & $p$ value \\
\hline Age (years) & $58.7 \pm 5.6$ & $58.8 \pm 5.3$ & 0.62 \\
\hline Current smoker, n (\%) & $78(4.5)$ & $36(4.7)$ & 0.88 \\
\hline $\begin{array}{l}\text { Educational attainment, } \\
\mathrm{n}(\%)\end{array}$ & & & 0.48 \\
\hline $0-6$ & $448(26.0)$ & $202(26.3)$ & \\
\hline $7-9$ & $781(45.3)$ & $363(47.3)$ & \\
\hline$\geq 10$ & $495(28.7)$ & $203(26.4)$ & \\
\hline Physical activity, n (\%) & & & 0.52 \\
\hline Low & $1258(73.0)$ & $577(75.1)$ & \\
\hline Moderate & $343(19.9)$ & $139(18.1)$ & \\
\hline High & $123(7.1)$ & $52(6.8)$ & \\
\hline $\mathrm{BMI}\left(\mathrm{kg} / \mathrm{m}^{2}\right)$ & $22.22 \pm 1.61$ & $23.27 \pm 1.40$ & $<0.001$ \\
\hline Waist circumference $(\mathrm{cm})$ & $78.2 \pm 7.1$ & $82.6 \pm 6.6$ & $<0.001$ \\
\hline $\mathrm{SBP}(\mathrm{mmHg})$ & $127.77 \pm 18.13$ & $131.27 \pm 18.57$ & $<0.001$ \\
\hline $\mathrm{DBP}(\mathrm{mmHg})$ & $77.15 \pm 9.73$ & $79.47 \pm 9.66$ & $<0.001$ \\
\hline FPG (mmol/L) & $6.00 \pm 1.36$ & $6.68 \pm 2.06$ & $<0.001$ \\
\hline PPG (mmol/L) & $7.96 \pm 3.25$ & $9.87 \pm 4.47$ & $<0.001$ \\
\hline $\mathrm{HbA}_{1 \mathrm{c}}(\%)$ & $5.90 \pm 0.84$ & $6.30 \pm 1.22$ & $<0.001$ \\
\hline HOMA-IR & $1.49(1.16-1.93)$ & $2.29(1.65-2.97)$ & $<0.001$ \\
\hline $\mathrm{HDL}-\mathrm{C}(\mathrm{mmol} / \mathrm{L})$ & $1.33 \pm 0.32$ & $1.19 \pm 0.30$ & $<0.001$ \\
\hline LDL-C (mmol/L) & $2.67 \pm 0.76$ & $2.71 \pm 0.82$ & 0.174 \\
\hline Total cholesterol (mmol/L) & $4.74 \pm 1.00$ & $4.86 \pm 1.06$ & 0.011 \\
\hline Triglycerides (mmol/L) & $1.18(0.89-1.60)$ & $1.71(1.21-2.50)$ & $<0.001$ \\
\hline $\operatorname{ALT}(\mathrm{U} / \mathrm{L})$ & $12(9-16)$ & $15(11-23)$ & $<0.001$ \\
\hline AST (U/L) & $18(15-22)$ & $19(16-24)$ & 0.004 \\
\hline $\mathrm{GGT}(\mathrm{U} / \mathrm{L})$ & $15(11-20)$ & $20(14-31)$ & $<0.001$ \\
\hline CRP (mg/L) & $1.09(0.58-2.01)$ & $2.04(1.10-3.16)$ & $<0.001$ \\
\hline Adiponectin (mg/L) & $3.81 \pm 1.17$ & $3.19 \pm 0.97$ & $<0.001$ \\
\hline Neck circumference (cm) & $32.0 \pm 2.4$ & $33.4 \pm 2.6$ & $<0.001$ \\
\hline
\end{tabular}

$\mathrm{ALT}$, alanine aminotransferase; $\mathrm{AST}$, aspartate transaminase; $\mathrm{BMI}$, body mass index; CRP, C-reactive protein; DBP, diastolic blood pressure; FPG, fasting plasma glucose; GGT, $\mathrm{Y}$-glutamyltransferase; $\mathrm{HbA}_{1 c^{\prime}}$ glycated hemoglobin; $\mathrm{HDL}-\mathrm{C}$, high-density lipoprotein cholesterol; HOMA-IR, homeostasis model assessmentinsulin resistance; LDL-C, low-density lipoprotein cholesterol; PPG, postprandial plasma glucose; SBP, systolic blood pressure

of NAFLD raised sharply from the lowest tertile to the highest tertile group $(15.9 \%, 29.7 \%, 47.5 \%$, respectively). According to logistic regression analyses, large neck circumference was associated with the presence of NAFLD (odds ratio, 2.28; 95\% CI, 1.74-2.98; highest versus lowest tertile, $p<0.001$ ) after adjustment for age, smoking status, physical activity, educational attainment, BMI, waist circumference, HOMA-IR, CRP, adiponectin, fasting plasma glucose, post-loading plasma glucose, systolic blood pressure, diastolic blood pressure, lipid profiles, and liver enzymes (Table 2). 
Table 2 Presence of nonalcoholic fatty liver diseases in relation to neck circumference tertiles $(n=2492)$

\begin{tabular}{|c|c|c|c|c|}
\hline & \multicolumn{3}{|c|}{ Neck circumference } & \multirow[t]{2}{*}{$p$ for trend } \\
\hline & $\begin{array}{l}\text { Tertile } 1 \\
(n=830)\end{array}$ & $\begin{array}{l}\text { Tertile 2 } \\
(\mathrm{n}=831)\end{array}$ & $\begin{array}{l}\text { Tertile } 3 \\
(n=831)\end{array}$ & \\
\hline Prevalence of NAFLD (\%) & $132(15.9)$ & $247(29.7)$ & $395(47.5)$ & $<0.001$ \\
\hline Model 1 OR (95\% Cl) & 1.00 & $2.24(1.77-2.84)$ & $4.79(3.80-6.04)$ & $<0.001$ \\
\hline Model 2 OR (95\% Cl) & 1.00 & $1.80(1.41-2.30)$ & $3.52(2.76-4.48)$ & $<0.001$ \\
\hline Model 3 OR (95\% Cl) & 1.00 & $1.70(1.33-2.18)$ & $3.05(2.38-3.92)$ & $<0.001$ \\
\hline Model 4 OR (95\% Cl) & 1.00 & $1.64(1.28-2.10)$ & $2.84(2.21-3.65)$ & $<0.001$ \\
\hline Model 5 OR (95\% Cl) & 1.00 & $1.42(1.09-1.85)$ & $2.28(1.74-2.98)$ & $<0.001$ \\
\hline
\end{tabular}

Model 1 was adjusted for age, smoking status, physical activity, and educational attainment. Model 2 was further adjusted for BMI and waist circumference. Model 3 was further adjusted for HOMA-IR, CRP, and adiponectin. Model 4 was further adjusted for model 3 variables and fasting glucose, post-loading plasma glucose, systolic blood pressure, diastolic blood pressure. Model 5 was further adjusted for lipid profiles and liver enzymes

\section{Association between baseline neck circumference} and the incidence of NAFLD in the follow-up investigation During a 3.1-year follow-up period, 429 participants developed NAFLD. The clinical characteristics of the study subjects are presented in Table 3. No statistically significant difference in baseline characteristics was found between those retained and those lost to follow-up (Additional file 1: Table S1). According to Pearson correlations analyses, the neck circumference was positively correlated with BMI, waist circumference, triglycerides, HOMA-IR, and CRP. In contrast, neck circumference was negatively correlated with HDL-C and adiponectin (Table 4). The associations were still significant even after adjustment for age, smoking, physical activity, educational attainment, BMI, and waist circumference $(p<0.05)$.

We used Cox regression analysis with the lowest neck circumference tertile group as a reference to assess the relationship between neck circumference and the risk of incident NAFLD. As presented in Table 5, the HRs for incident NAFLD was higher with increasing neck circumference tertiles. In the highest neck circumference tertile, the HR was 2.16 (95\% CI 1.60-2.92; $p$ for trend $<0.001$ ) for incident NAFLD after adjusting for age, smoking, physical activity, and educational attainment (model 1). Interestingly, further adjustment for BMI and waist circumference (model 2) only slightly reduced the magnitude of the HRs for incident NAFLD. Furthermore, there were still statistically significant (HR 1.42; 95\% CI 1.15-1.97; $p$ for trend $=0.004$ ) by additional adjustment for HOMA-IR, CRP, adiponectin, glucose parameters, systolic blood pressure, diastolic blood pressure, lipid profiles, and liver enzymes (model 5). When neck circumference was considered as a continuous variable, the overall HR (95\% CI) of having NAFLD was 1.22 (1.10-1.41) per 1-SD increment of neck circumference. A positive linear circumference-response relationship was evident in the cubic spline regression model (Fig. 2, p for nonlinearity $>0.1$ ).

Considering the contribution of general obesity, abdominal obesity, and insulin resistance to the development of NAFLD, we further evaluated the combined effect of neck circumference with BMI, waist circumference, and HOMA-IR on fatty liver, respectively. The positive association between neck circumference and risk of incident NAFLD remained consistent across a wide range of BMI, waist circumference, and HOMA-IR (Fig. 3). And subjects with larger neck circumference combine with higher BMI, waist circumference, or HOMA-IR have a substantially increased incidence of NAFLD.

\section{Subgroup analyses \\ Stratified analyses of the associations between per 1-SD increment in neck circumference and nonalcoholic fatty liver disease}

Subgroup analyses were performed to examine potential effect modifiers, stratified by age, BMI, waist circumference, CRP, diabetes status, and physical activity. In the stratified analyses, the positive associations between per 1-SD increment in neck circumference and the risk of incident NAFLD remained consistent across all subgroups (Fig. 4). No interaction was observed with any of the variables (all p for interaction $>0.1$ ).

\section{Discussion}

In the present study, we observed that relatively large neck circumference was associated with the prevalence and incidence of NAFLD among postmenopausal women with normal BMI. Higher neck fat accumulation was also associated with metabolic dysregulation and inflammation characterized by insulin resistance, elevated triglycerides, and CRP. Collectively, these findings indicate the importance of excessive neck fat accumulation to predict 
Table 3 Baseline characteristics of subjects with or without development of nonalcoholic fatty liver diseases at 3.1 years $(n=1354)$

\begin{tabular}{|c|c|c|c|}
\hline Variables & $\begin{array}{l}\text { Non-NAFLD } \\
(\mathrm{n}=925)\end{array}$ & $\begin{array}{l}\text { NAFLD } \\
(n=429)\end{array}$ & $p$ value \\
\hline Age (years) & $58.6 \pm 5.7$ & $58.7 \pm 5.5$ & 0.678 \\
\hline Current smoker, n (\%) & $50(5.4)$ & $19(4.4)$ & 0.34 \\
\hline $\begin{array}{l}\text { Educational attainment, } \\
\text { n(\%) }\end{array}$ & & & 0.26 \\
\hline $0-6$ & $235(25.4)$ & $120(28.0)$ & \\
\hline $7-9$ & $419(45.3)$ & $201(46.9)$ & \\
\hline$\geq 10$ & $271(29.3)$ & $108(25.2)$ & \\
\hline Physical activity, n (\%) & & & 0.95 \\
\hline Low & $672(72.6)$ & $308(71.8)$ & \\
\hline Moderate & $189(20.4)$ & $90(21.0)$ & \\
\hline High & $64(6.9)$ & $31(7.2)$ & \\
\hline $\mathrm{BMI}\left(\mathrm{kg} / \mathrm{m}^{2}\right)$ & $21.95 \pm 1.61$ & $22.79 \pm 1.48$ & $<0.001$ \\
\hline Waist circumference $(\mathrm{cm})$ & $77.3 \pm 6.7$ & $80.5 \pm 6.1$ & $<0.001$ \\
\hline $\mathrm{SBP}(\mathrm{mmHg})$ & $126.91 \pm 17.89$ & $129.38 \pm 18.29$ & 0.023 \\
\hline $\mathrm{DBP}(\mathrm{mmHg})$ & $76.95 \pm 9.66$ & $78.21 \pm 9.70$ & 0.031 \\
\hline $\mathrm{FPG}(\mathrm{mmol} / \mathrm{L})$ & $5.88 \pm 1.20$ & $6.20 \pm 1.55$ & $<0.001$ \\
\hline PPG (mmol/L) & $7.61 \pm 2.95$ & $8.48 \pm 3.42$ & $<0.001$ \\
\hline $\mathrm{HbA}_{1 c}(\%)$ & $5.84 \pm 0.71$ & $5.93 \pm 0.96$ & 0.104 \\
\hline HOMA-IR & $1.36(1.00-1.79)$ & $1.72(1.36-2.41)$ & $<0.001$ \\
\hline $\mathrm{HDL}-\mathrm{C}(\mathrm{mmol} / \mathrm{L})$ & $1.36 \pm 0.34$ & $1.28 \pm 0.31$ & $<0.001$ \\
\hline $\mathrm{LDL}-\mathrm{C}(\mathrm{mmol} / \mathrm{L})$ & $2.67 \pm 0.77$ & $2.70 \pm 0.76$ & 0.552 \\
\hline Total cholesterol (mmol/L) & $4.75 \pm 1.03$ & $4.80 \pm 1.00$ & 0.464 \\
\hline Triglycerides (mmol/L) & $1.14(0.86-1.51)$ & $1.40(0.99-1.96)$ & $<0.001$ \\
\hline $\mathrm{ALT}(\mathrm{U} / \mathrm{L})$ & $11(8-15)$ & $13(10-16)$ & $<0.001$ \\
\hline AST (U/L) & $19(15-23)$ & $19(15-22)$ & 0.781 \\
\hline GGT (U/L) & $14(11-19)$ & $16(12-23)$ & $<0.001$ \\
\hline $\mathrm{CRP}(\mathrm{mg} / \mathrm{L})$ & $1.04(0.57-1.95)$ & $1.28(0.68-2.40)$ & $<0.001$ \\
\hline Adiponectin (mg/L) & $3.98 \pm 1.16$ & $3.46 \pm 1.13$ & $<0.001$ \\
\hline Neck circumference (cm) & $31.6 \pm 2.2$ & $32.4 \pm 2.2$ & $<0.001$ \\
\hline
\end{tabular}

ALT, alanine aminotransferase; AST, aspartate transaminase; $\mathrm{BMI}$, body mass index; CRP, C-reactive protein; DBP, diastolic blood pressure; FPG, fasting plasma glucose; GGT, Y-glutamyltransferase; HbA1c, glycated hemoglobin; HDL-C, high-density lipoprotein cholesterol; HOMA-IR, homeostasis model assessmentinsulin resistance; LDL-C, low-density lipoprotein cholesterol; PPG, postprandial plasma glucose; SBP, systolic blood pressure

the development of NAFLD among postmenopausal women with normal BMI.

Epidemiological studies have shown that sex and menopause affect the prevalence and incidence of NAFLD [14]. In women, the relations between visceral fat accumulation and metabolic profile were greater than in men [15]. Furthermore, as age increases and estrogen levels decrease, women after menopause are prone to insulin resistance, hyperlipidemia, and visceral fat accumulation $[16,17]$, all of which are known risk factors for NAFLD. The robust protective role of estrogens was revealed in epidemiological studies, where the prevalence of NAFLD
Table 4 Correlations between baseline neck circumference and metabolic characteristics

\begin{tabular}{|c|c|c|c|c|}
\hline \multirow[t]{3}{*}{ Variables } & \multicolumn{4}{|c|}{ Neck circumference } \\
\hline & \multicolumn{2}{|c|}{ Univariate } & \multicolumn{2}{|c|}{ Multivariate } \\
\hline & Beta & $p$ value & Beta & $p$ value \\
\hline Body mass index & 0.230 & $<0.001$ & - & - \\
\hline Waist circumference & 0.313 & $<0.001$ & - & - \\
\hline $\mathrm{HDL}-\mathrm{C}$ & -0.144 & $<0.001$ & -0.12 & $<0.001$ \\
\hline Triglycerides & 0.104 & $<0.001$ & 0.11 & $<0.001$ \\
\hline HOMA-IR & 0.128 & $<0.001$ & 0.18 & $<0.001$ \\
\hline CRP & 0.103 & 0.002 & 0.10 & 0.003 \\
\hline Adiponectin & -0.110 & $<0.001$ & -0.09 & 0.007 \\
\hline
\end{tabular}

Multivariable model was adjusted for age, smoking, physical activity, educational attainment, body mass index, and waist circumference. CRP, C-reactive protein; HDL-C, high-density lipoprotein cholesterol; HOMA-IR, homeostasis model assessment-insulin resistance

Table 5 Incidence of NAFLD in relation to neck circumference $(n=1354)$

\begin{tabular}{|c|c|c|c|c|c|}
\hline \multirow[t]{3}{*}{ NAFLD } & \multicolumn{5}{|c|}{ Neck circumference } \\
\hline & \multicolumn{3}{|c|}{ Highest tertile versus lowest tertile } & \multicolumn{2}{|c|}{$\begin{array}{l}\text { Per } 1 \mathrm{SD} \text {, as } \\
\text { continuous variable }\end{array}$} \\
\hline & Reference & $\mathrm{HR}(95 \% \mathrm{Cl})$ & $p$ for trend & $\mathrm{HR}(95 \% \mathrm{Cl})$ & $p$ value \\
\hline Model 1 & 1.00 & $\begin{array}{l}2.16 \\
(1.60-2.92)\end{array}$ & $<0.001$ & $\begin{array}{l}1.44 \\
(1.27-1.65)\end{array}$ & $<0.001$ \\
\hline Model 2 & 1.00 & $\begin{array}{l}1.79 \\
(1.31-2.46)\end{array}$ & $<0.001$ & $\begin{array}{l}1.36 \\
(1.21-1.58)\end{array}$ & $<0.001$ \\
\hline Model 3 & 1.00 & $\begin{array}{l}1.66 \\
(1.21-2.27)\end{array}$ & $<0.001$ & $\begin{array}{l}1.30 \\
(1.13-1.49)\end{array}$ & $<0.001$ \\
\hline Model 4 & 1.00 & $\begin{array}{l}1.51 \\
(1.17-2.09)\end{array}$ & 0.001 & $\begin{array}{l}1.25 \\
(1.12-1.44)\end{array}$ & 0.002 \\
\hline Model 5 & 1.00 & $\begin{array}{l}1.42 \\
(1.15-1.97)\end{array}$ & 0.004 & $\begin{array}{l}1.22 \\
(1.10-1.41)\end{array}$ & 0.006 \\
\hline
\end{tabular}

Model 1 was adjusted for age, smoking status, physical activity, and educational attainment. Model 2 was further adjusted for BMI and waist circumference. Model 3 was further adjusted for HOMA-IR, CRP, and adiponectin. Model 4 was further adjusted for model 3 variables and fasting glucose, post-loading plasma glucose, systolic blood pressure, diastolic blood pressure. Model 5 was further adjusted for lipid profiles and liver enzymes

is lower in premenopausal women compared to men or postmenopausal women [18]. As the main circulating estrogen, $17 \beta$-estradiol has effects beyond reproductive health. In insulin-sensitive tissues like skeletal muscle, $17 \beta$-estradiol receptor $\alpha$ has a positive effect on insulin signaling and glucose transporter-4 expression [19], which indicates that $17 \beta$-estradiol may directly regulate insulin action. Meanwhile, another study showed that exposure to $17 \beta$-estradiol restores insulin sensitivity and glucose tolerance in high-fat diet-fed ovariectomized mice [20]. In addition to insulin sensitivity, estrogens can 


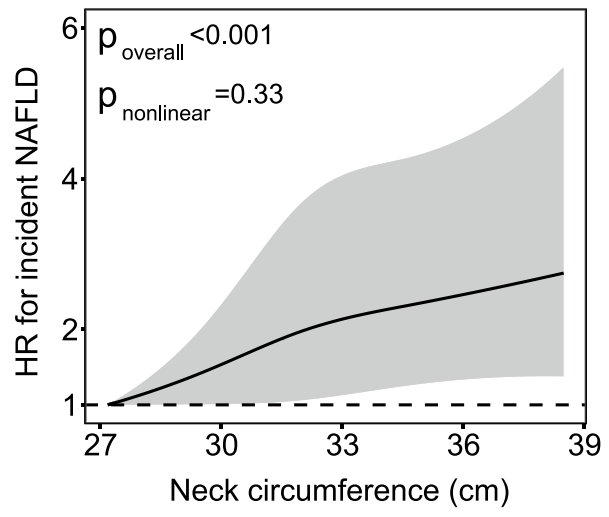

Fig. 2 Neck circumference on a continuous scale and risk of incident nonalcoholic fatty liver diseases. Data were fit by a Cox regression model based on restricted cubic splines with 5 knots at the 5th, 35th, 50th, 65th, and 95th percentiles. The solid line represents the hazard ratio and the gray area represents the $95 \%$ confidence interval. Model was adjusted for age, smoking status, physical activity, educational attainment, BMI, waist circumference, HOMA-IR, CRP, adiponectin, fasting plasma glucose, post-loading plasma glucose, systolic blood pressure, diastolic blood pressure, lipid profiles, and liver enzymes

also affect adipose tissue metabolism, energy expenditure, and hepatic glucogenesis [21]. Collectively, the protective effect of estrogen on NAFLD is a combination of multiple factors and its underlying mechanism remains to be further studied.

Previous researches reported that higher BMI, waist circumference, HOMA-IR, elevated triglyceride levels, and reduced HDL-cholesterol levels were associated with NAFLD among non-obese individuals [22]. In our study, neck circumference was significantly correlated with BMI, waist circumference, HOMA-IR, and triglycerides, and negatively correlated with HDL-C, consistent with previous studies [7, 23]. Moreover, the positive association between neck circumference and incidence of NAFLD remained consistent across a wide range of BMI, waist circumference, and HOMA-IR among postmenopausal women with normal weight. Additionally, previous cross-sectional studies have shown that neck circumference was an independent predictor for NAFLD in the general population [24] and non-obese men [25]. Our strong evidence indicating the relation of neck circumference and incidence of NAFLD even in postmenopausal women with normal BMI may validate their results and provide valuable clues for further studies.

It is well established that obesity is a heterogeneous disorder. BMI is a common screening measure to identify subjects with abnormal body fat distribution. However, BMI cannot provide accurate information about the regional distribution of body fat. Moreover, subjects within the same BMI could have considerable differences in the amount and distribution of regional fat accumulation. Previous studies have demonstrated that differences in body fat distribution result in specific metabolic complications [26, 27]. Thus, neck circumference, a proxy of neck subcutaneous fat, began to show diagnostic value for evaluating metabolic disturbances.

As an alternative measurement of upper-body subcutaneous fat, neck circumference is a great indicator of ectopic fat distribution. Subcutaneous fat in the upper body accounts for a much greater proportion of systemic free fatty acids released and is more lipolytically active than lower body adipose tissue [7]. Large neck circumference means excessive accumulation of subcutaneous fat in the neck, which contributes to a greater flux of the free fatty acid released into the circulation. Subsequently, elevated free fatty acid contributes to increased synthesis and ectopic deposition of triglycerides, insulin
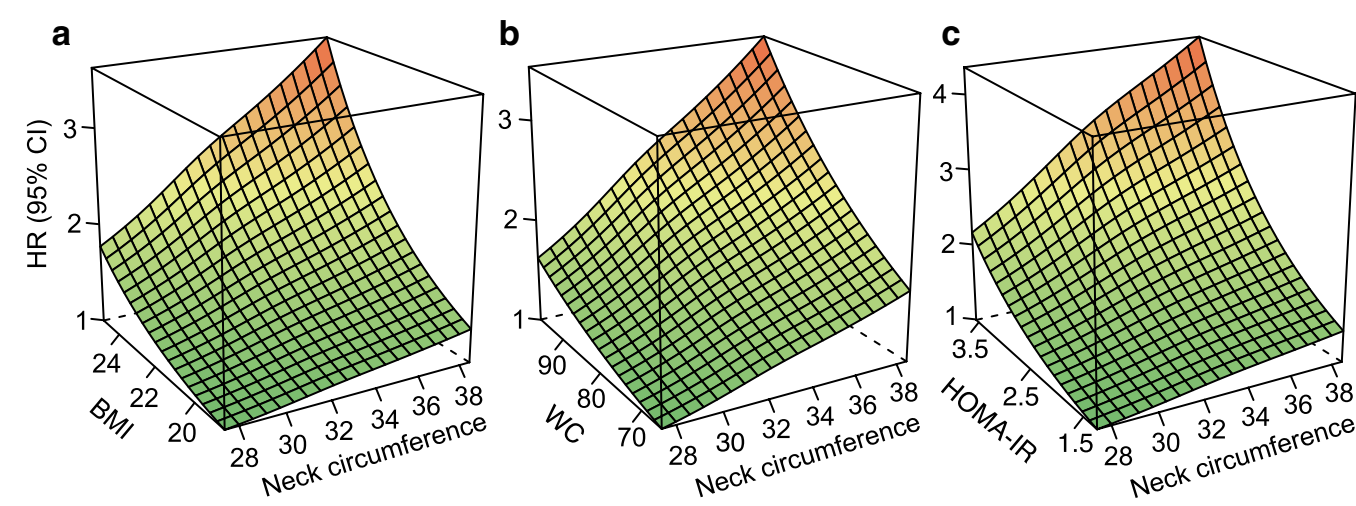

Fig. 3. 3-Dimensional nonalcoholic fatty liver diseases prediction plot. Prediction plot as a function of neck circumference levels ( $x$-axis), BMI (y-axis) $(\mathbf{a})$, waist circumference (y-axis) (b), and HOMA-IR (y-axis) (c) with the hazard ratio of incident nonalcoholic fatty liver diseases presented on the z-axis. BMI, body mass index; WC, waist circumference; HOMA-IR, homeostasis model assessment-insulin resistance 


\begin{tabular}{|c|c|c|c|}
\hline Subgroups & & $\mathrm{HR}(95 \% \mathrm{Cl})$ & $P$ for interaction \\
\hline Age (years) & & & 0.11 \\
\hline$<65$ & - & $1.19(1.05-1.39)$ & \\
\hline$\geq 65$ & -1 & $1.46(1.21-1.78)$ & \\
\hline BMI $\left(\mathrm{kg} / \mathrm{m}^{2}\right)$ & & & 0.42 \\
\hline$<23$ & $\rightarrow-$ & $1.26(1.06-1.48)$ & \\
\hline$\geq 23$ & -1 & $1.23(1.05-1.47)$ & \\
\hline Waist (cm) & & & 0.13 \\
\hline$<80$ & - & $1.21(1.03-1.42)$ & \\
\hline$\geq 80$ & $\rightarrow-$ & $1.38(1.12-1.68)$ & \\
\hline CRP (mg/L) & & & 0.24 \\
\hline$<3.0$ & -1 & $1.25(1.04-1.52)$ & \\
\hline$\geq 3.0$ & 要 & $1.49(1.13-2.05)$ & \\
\hline Diabetes & & & 0.38 \\
\hline No & $\rightarrow-$ & $1.24(1.06-1.46)$ & \\
\hline Yes & a & $1.15(0.94-1.57)$ & \\
\hline Physical activity & & & 0.46 \\
\hline Low & $\rightarrow-$ & $1.35(1.13-1.63)$ & \\
\hline Moderate & -1 & $1.19(0.96-1.70)$ & \\
\hline High & & $1.41(1.01-1.92)$ & \\
\hline & $\begin{array}{l}1 \\
2\end{array}$ & 3 & \\
\hline \multicolumn{4}{|c|}{$\begin{array}{l}\text { Fig. } 4 \text { Stratified analyses of the associations between per 1-SD } \\
\text { increment in neck circumference and nonalcoholic fatty liver disease. } \\
\text { Model was adjusted for age, smoking status, physical activity, } \\
\text { educational attainment, BMl, waist circumference, HOMA-IR, CRP, } \\
\text { adiponectin, fasting plasma glucose, post-loading plasma glucose, } \\
\text { systolic blood pressure, diastolic blood pressure, lipid profiles, and } \\
\text { liver enzymes }\end{array}$} \\
\hline
\end{tabular}

resistance, and inflammation [28]. In addition, increased free fatty acids are involved in impaired glucose homeostasis by inhibiting glucose uptake, oxidation, glycogen synthesis, and increasing output hepatic glucose [29]. Concomitantly, excessive free fatty acids could trigger oxidative stress, an early instigator of NAFLD [30], and endoplasmic reticulum stress which intersects with various inflammatory and stress signaling pathways through unfolded protein response [31]. The excessive free fatty acids release derived from neck subcutaneous adipose might be a potential link between neck circumference and NAFLD.

In our study, neck circumference was positively correlated with C-reactive protein, and negatively correlated with adiponectin. As we best known, the abnormal accumulation of fat is associated with adipose tissue metabolic capacities, endocrine, and immune function, which along with altered lipid mediators, adipokines, pro- or anti-inflammatory cytokines, and impaired signaling pathways that are involved in metabolic abnormalities [32]. In addition to being a depot of fat, the adipose tissue is also a highly active endocrine organ, secreting various biologically active molecules, collectively termed adipokines [33]. When adipose tissue expands, the capacity of adipocytes to act as endocrine cells and secrete a variety of adipokines is altered in subjects with NAFLD [34]. These altered kinds and levels of adipokine are associated with dysregulation of triglyceride, fatty acids metabolism, and insulin resistance [35]. Moreover, due to excessive fat accumulation and substantial infiltration of immune cells, a specific crown-like disposition of macrophages around single necrotic adipocytes occurs in subjects with NAFLD [36]. Subsequently, proinflammatory pathways were activated, and a variety of proinflammatory cytokines and chemokines were overflowed that contribute to low-grade inflammation and insulin resistance [32]. In general, adipose dysfunctions, inflammation, and stress partly linking neck obesity to insulin resistance and NAFLD.

Several potential limitations of the current study should also be noted. First, we did not quantify the tissue composition of the neck. The use of neck circumference to assess the neck subcutaneous fat was a convenient and practical way but was unable to quantify the fat accumulation and muscle mass. Hence, the amount and size of subcutaneous adipocyte and muscle fat are unclear. Second, due to ultrasonographic examination was performed to determine the presence of NAFLD, the sensitivity of liver ultrasonography may vary depending on the hepatic fat content. Nevertheless, when performed properly, ultrasonography has been reported to detect as little as $\geq 5 \%$ hepatic fat content. Although as discussed above, liver ultrasonography offers several strengths including the non-invasive nature of the test, portability, low cost, and simplicity of use, make it further applicable and acceptable in large-scale epidemiological studies, particularly in developing countries. Third, given the diagnosis of NAFLD was based on ultrasound imaging, NAFLD patients in our study were in at least a moderate stage of the disease. Therefore, in the present study, we were unable to determine the relationship between neck circumference and mild-stage NAFLD. Fourth, we did not assess the impact of excluded data on the relationship between neck circumference and incident NAFLD.

\section{Conclusions}

Large neck circumference was significantly associated with an increased risk of NAFLD among postmenopausal women with normal BMI. Measurement of neck circumference may provide a more complete understanding of NAFLD risk associated with variation in fat distribution among postmenopausal women with normal BMI. 


\section{Abbreviations}

ALT: Alanine aminotransferase; AST: Aspartate transaminase; BMI: Body mass index; CRP: C-reactive protein; DBP: Diastolic blood pressure; FPG: Fasting plasma glucose; GGT: $\gamma$-Glutamyltransferase; $\mathrm{HbA}_{1 c}$ : Glycated hemoglobin; HDL-C: High-density lipoprotein cholesterol; HOMA-IR: Homeostasis mode assessment-insulin resistance; LDL-C: Low-density lipoprotein cholesterol; NAFLD: Nonalcoholic fatty liver disease; PPG: Postprandial plasma glucose; SBP: Systolic blood pressure; WC: Waist circumference.

\section{Supplementary Information}

The online version contains supplementary material available at https://doi. org/10.1186/s12986-021-00562-3.

Additional file 1: Supplementary Table S1. Baseline characteristics of study participants.

\section{Acknowledgements}

The authors gratefully acknowledge the support of the study participants, study staff, and partner organizations participating in the baseline survey and follow-up investigation.

\section{Authors' contributions}

$J S, Z W$, and WZ drafted the manuscript and performed the experiments. ZY, $J F, Q S, L Q$, and GN conceived and designed the study. WZ, YN, XL, HZ, and NL recruited the subjects, processed samples, and contributed to the acquisition of data. JS and ZY analyzed the data. ZY revised the manuscript. All authors read and approved the final manuscript.

\section{Funding}

This work was supported by the National Natural Science Foundation of China (81970669, 81873565, 81670743, 81370953), the National Key Research and Development Plan 'Precision Medicine Research' (2017YFSF090203), the Shanghai Health System Outstanding Young Talents Training Program (XYQ2013098), the Shanghai Sailing Program (18YF1415800), the Shanghai Health and Family Planning Commission (21740173).

\section{Availability of data and materials}

The datasets generated during and/or analyzed during the current study are not publicly available but are available from the corresponding author on reasonable request.

\section{Declarations}

\section{Ethics approval and consent to participate}

The study protocol was approved by the Ethics Committee of Xinhua Hospital Affiliated to Shanghai Jiao Tong University School of Medicine. Written informed consent was obtained from all participants before data collection.

\section{Consent for publication}

Not applicable.

\section{Competing interests}

No potential conflicts of interest relevant to this article were reported.

\section{Author details}

${ }^{1}$ Department of Endocrinology, Xinhua Hospital, Shanghai Jiao Tong University School of Medicine, Shanghai, China. ${ }^{2}$ Department of Gastroenterology, Shanghai Key Laboratory of Children's Digestion and Nutrition, Xinhua Hospital, Shanghai Jiao Tong University School of Medicine, Shanghai, China. ${ }^{3}$ Shanghai National Clinical Research Center for Endocrine and Metabolic Diseases, Key Laboratory for Endocrine and Metabolic Diseases of the National Health Commission of the PR China, Shanghai Institute of Endocrine and Metabolic Diseases, Ruijin Hospital, Shanghai Jiao Tong University School of Medicine, Shanghai, China.

Received: 13 November 2020 Accepted: 8 March 2021

Published online: 17 March 2021

\section{References}

1. Bellentani S, Saccoccio G, Masutti F, Crocè LS, Brandi G, Sasso F, Cristanini G, Tiribelli C. Prevalence of and risk factors for hepatic steatosis in Northern Italy. Ann Intern Med. 2000;132:112-7.

2. Silverman JF, O'Brien KF, Long S, Leggett N, Khazanie PG, Pories WJ, Norris $H T$, Caro JF. Liver pathology in morbidly obese patients with and without diabetes. Am J Gastroenterol. 1990:85:1349-55.

3. Fan J-G, Kim S-U. Wong VW-S: New trends on obesity and NAFLD in Asia. J Hepatol. 2017:67:862-73.

4. Tchkonia T, Thomou T, Zhu Y, Karagiannides I, Pothoulakis C, Jensen MD, Kirkland JL. Mechanisms and metabolic implications of regional differences among fat depots. Cell Metab. 2013;17:644-56.

5. Romero-Corral A, Somers VK, Sierra-Johnson J, Korenfeld Y, Boarin S, Korinek J, Jensen MD, Parati G, Lopez-Jimenez F. Normal weight obesity: a risk factor for cardiometabolic dysregulation and cardiovascular mortality. Eur Heart J. 2010;31:737-46.

6. Nielsen S, Guo Z, Johnson CM, Hensrud DD, Jensen MD. Splanchnic lipolysis in human obesity. J Clin Investig. 2004;113:1582-8.

7. Preis SR, Massaro JM, Hoffmann U, D’Agostino RB, Levy D, Robins SJ, Meigs JB, Vasan RS, O'Donnell CJ, Fox CS. Neck circumference as a novel measure of cardiometabolic risk: the Framingham Heart study. J Clin Endocrinol Metab. 2010:95:3701-10.

8. Zhou JY, Ge H, Zhu MF, Wang LJ, Chen L, Tan YZ, Chen YM, Zhu HL. Neck circumference as an independent predictive contributor to cardio-metabolic syndrome. Cardiovasc Diabetol. 2013;12:76

9. JafariNasabian P, Inglis JE, Reilly W, Kelly OJ, Ilich JZ. Aging human body: changes in bone, muscle and body fat with consequent changes in nutrient intake. J Endocrinol. 2017;234:R37-51.

10. Lu J, He J, Li M, Tang X, Hu R, Shi L, Su Q, Peng K, Xu M, Xu Y, et al. Predictive value of fasting glucose, postload glucose, and hemoglobin a on risk of diabetes and complications in Chinese adults. Diabetes Care. 2019:42:1539-48

11. Wang T, Lu J, Su Q, Chen Y, Bi Y, Mu Y, Chen L, Hu R, Tang X, Yu X, et al. Ideal cardiovascular health metrics and major cardiovascular events in patients with prediabetes and diabetes. JAMA Cardiology. 2019;4:874-83.

12. Chitturi S, Farrell GC, Hashimoto E, Saibara T, Lau GKK, Sollano JD. Nonalcoholic fatty liver disease in the Asia-Pacific region: definitions and overview of proposed quidelines. J Gastroenterol Hepatol. 2007;22:778-87.

13. Matthews DR, Hosker JP, Rudenski AS, Naylor BA, Treacher DF, Turner RC. Homeostasis model assessment: insulin resistance and beta-cell function from fasting plasma glucose and insulin concentrations in man. Diabetologia. 1985;28:412-9.

14. Suzuki A, Abdelmalek MF. Nonalcoholic fatty liver disease in women. Womens Health (Lond Engl). 2009;5:191-203.

15. Fox CS, Massaro JM, Hoffmann U, Pou KM, Maurovich-Horvat P, Liu C-Y, Vasan RS, Murabito JM, Meigs JB, Cupples LA, et al. Abdominal visceral and subcutaneous adipose tissue compartments: association with metabolic risk factors in the Framingham Heart Study. Circulation. 2007:116:39-48.

16. Lovejoy JC, Champagne CM, de Jonge L, Xie H, Smith SR. Increased visceral fat and decreased energy expenditure during the menopausal transition. Int J Obes. 2005;2008(32):949-58.

17. Gupte AA, Pownall HJ, Hamilton DJ. Estrogen: an emerging regulator of insulin action and mitochondrial function. Journal of Diabetes Research. 2015:2015:916585.

18. Browning JD, Szczepaniak LS, Dobbins R, Nuremberg P, Horton JD, Cohen JC, Grundy SM, Hobbs HH. Prevalence of hepatic steatosis in an urban population in the United States: impact of ethnicity. Hepatology. 2004:40:1387-95.

19. Barros RP, Gabbi C, Morani A, Warner M, Gustafsson JA. Participation of ERalpha and ERbeta in glucose homeostasis in skeletal muscle and white adipose tissue. Am J Physiol Endocrinol Metab. 2009;297:E124-133.

20. Riant E, Waget A, Cogo H, Arnal JF, Burcelin R, Gourdy P. Estrogens protect against high-fat diet-induced insulin resistance and glucose intolerance in mice. Endocrinology. 2009;150:2109-17.

21. Gupte AA, Pownall HJ, Hamilton DJ. Estrogen: an emerging regulator of insulin action and mitochondrial function. J Diabetes Res. 2015:2015:916585.

22. Wei JL, Leung JC-F, Loong TC-W, Wong GL-H, Yeung DK-W, Chan RS-M, Chan HL-Y, Chim AM-L, Woo J, Chu WC-W, Wong VW-S. Prevalence and severity of nonalcoholic fatty liver disease in non-obese patients: a 
population study using proton-magnetic resonance spectroscopy. Am J Gastroenterol. 2015;110(9):1306-14.

23. Liang J, Teng F, Li Y, Liu X, Zou C, Wang Y, Li H, Qi L. neck circumference and insulin resistance in Chinese adults: the Cardiometabolic Risk in Chinese (CRC) Study. Diabetes Care. 2013;36:e145-146.

24. Huang B-X, Zhu M-f, Wu T, Zhou J-y, Liu Y, Chen X-I, Zhou R-f, Wang L-J, Chen $Y-m$, Zhu H-I. Neck circumference, along with other anthropometric indices, has an independent and additional contribution in predicting fatty liver disease. PLoS ONE. 2015;10:e0118071.

25. Li Q, Wang N, Han B, Chen Y, Zhu C, Chen Y, Xia F, Cang Z, Zhu C, Chen C, et al. Neck circumference as an independent indicator to non-alcoholic fatty liver disease in non-obese men. Nutr Metab. 2015;12:63.

26. Jensen MD, Haymond MW, Rizza RA, Cryer PE, Miles JM. Influence of body fat distribution on free fatty acid metabolism in obesity. J Clin Investig. 1989;83:1168-73.

27. Jensen MD. Role of body fat distribution and the metabolic complications of obesity. J Clin Endocrinol Metab. 2008;93:S57-63.

28. Hotamisligil GS. Inflammation, metaflammation and immunometabolic disorders. Nature. 2017;542:177-85.

29. Bergman RN, Ader M. Free fatty acids and pathogenesis of type 2 diabetes mellitus. Trends Endocrinol Metabol TEM. 2000;11:351-6.

30. Byrne CD, Targher G. NAFLD: a multisystem disease. J Hepatol. 2015;62:S47-64.

31. Hotamisligil GS. Endoplasmic reticulum stress and the inflammatory basis of metabolic disease. Cell. 2010;140:900-17.
32. Weisberg SP, McCann D, Desai M, Rosenbaum M, Leibel RL, Ferrante AW. Obesity is associated with macrophage accumulation in adipose tissue. J Clin Investig. 2003;112:1796-808.

33. Kershaw EE, Flier JS. Adipose tissue as an endocrine organ. J Clin Endocrinol Metab. 2004:89:2548-56.

34. Furukawa S, Fujita T, Shimabukuro M, Iwaki M, Yamada Y, Nakajima Y, Nakayama O, Makishima M, Matsuda M, Shimomura I. Increased oxidative stress in obesity and its impact on metabolic syndrome. J Clin Investig. 2004;114:1752-61.

35. Guilherme A, Virbasius JV, Puri V, Czech MP. Adipocyte dysfunctions linking obesity to insulin resistance and type 2 diabetes. Nat Rev Mol Cell Biol. 2008:9:367-77.

36. Cancello R, Henegar C, Viguerie N, Taleb S, Poitou C, Rouault C, Coupaye $M$, Pelloux V, Hugol D, Bouillot J-L, et al. Reduction of macrophage infiltration and chemoattractant gene expression changes in white adipose tissue of morbidly obese subjects after surgery-induced weight loss. Diabetes. 2005;54:2277-86.

\section{Publisher's Note}

Springer Nature remains neutral with regard to jurisdictional claims in published maps and institutional affiliations.
Ready to submit your research? Choose BMC and benefit from:

- fast, convenient online submission

- thorough peer review by experienced researchers in your field

- rapid publication on acceptance

- support for research data, including large and complex data types

- gold Open Access which fosters wider collaboration and increased citations

- maximum visibility for your research: over $100 \mathrm{M}$ website views per year

At BMC, research is always in progress.

Learn more biomedcentral.com/submissions 